\title{
Plumbagin induces RPE cell cycle arrest and apoptosis via p38 MARK and PI3K/AKT/ mTOR signaling pathways in PVR
}

\author{
Haiting Chen ${ }^{1,2}$, Huifang Wang ${ }^{1}$, Jianbin An ${ }^{1}$, Qingli Shang ${ }^{1}$ and Jingxue Ma ${ }^{1 *}$
}

\begin{abstract}
Background: This study aimed to explore the effects of plumbagin (PLB) on ARPE-19 cells and underlying mechanism.

Methods: Cultured ARPE-19 cells were treated with various concentrations $(0,5,15$, and $25 \mu \mathrm{M})$ of PLB for $24 \mathrm{~h}$ or with $15 \mu \mathrm{M}$ PLB for 12, 24 and $48 \mathrm{~h}$. Then cell viability was evaluated by MTT assay and DAPI staining, while apoptosis and cell cycle progression of ARPE cells were assessed by flow cytometric analysis. Furthermore, the level of main regulatory proteins was examinated by Western boltting and the expression of relative mRNA was tested by Real-Time PCR.

Results: PLB exhibited potent inducing effects on cell cycle arrest at G2/M phase and apoptosis of ARPE cells via the modulation of $\mathrm{BCl}-2$ family regulators in a concentration- and time-dependent manner. PLB induced inhibition of phosphatidylinositol 3-kinase (PI3K) and p38 mitogen-activated protein kinase (p38 MAPK) signaling pathways contributing to the anti-proliferative activities in ARPE cells.

Conclusions: This is the first report to show that PLB could inhibit the proliferation of RPE cells through downregulation of modulatory signaling pathways. The results open new avenues for the use of PLB in prevention and treatment of proliferative vitreoretinopathy.
\end{abstract}

Keywords: RPE, Plumbagin, Proliferation

\section{Background}

Proliferative vitreoretinopathy (PVR) is characterized by proliferation of cells and contraction of membranes on either retinal surface or in the vitreous cavity, which leads to retinal detachment and visual impairment [1]. It remains the most significant obstacle to successful retinal reattachment surgery, with a cumulative risk of $5 \%$ to $10 \%$ of all retinal detachment repairs, leading to poor functional results [2]. The most important cell type in PVR pathogenesis is the retinal pigment epithelial (RPE) cell, which is deemed to dedifferentiate and migrate through a retinal break and then proliferate on the retinal layers and vitrea, resulting in formation of epiretinal membranes [3].

\footnotetext{
* Correspondence: majingxue2000@163.com

${ }^{1}$ Department of Ophthalmology, Second Hospital of Hebei Medical University, No. 215 Peace West Road, Qiaoxi District, Shijiazhuang, Hebei 050000, China

Full list of author information is available at the end of the article
}

At present, vitrectomy is still the main method of PVR treatment. Although the equipment and operation skills have made tremendous progress in recent years, the surgical treatment is not ideal, and can not avoid recurrence, since vitrectomy itself is one of the common cause of PVR [4]. Therefore, more attempts have been made to develop nonsurgical therapies for PVR, especially pharmacological strategies.

Plumbagin (PLB; 5-hydroxy-2-methyl-1,4-naphthoquinone) is a kind of natural naphthoquinone component isolated from the root of Plumbago zeylanica L, which has a extensive range of effects including anti-inflammatory, anti-microbial, anti-cancer, anti-atherosclerotic, and neuroprotective in multiple cell lines and animal models [5]. Recently, the anti-proliferative effect of PLB has been a hot research topic. It has been proved in several studies that this effect may cause cell cycle arrest and apoptosis [6-9]. 
In the present study, we aimed to investigate whether PLB can effectively inhibit proliferation of human RPE (ARPE-19) cells in vitro and find out the underlying mechanism.

\section{Methods}

\section{Cell culture and treatment}

A human RPE cell line (ARPE-19) was purchase from American Type Culture Collection (ATCC; Manassas, VA, USA) and cultured in a DMEM/F12 medium supplemented with $10 \%$ FBS and regular antibiotics (1\% penicillin and streptomycin) (Gibco; Thermo Fisher Scientific, Inc., Waltham, MA, USA) at $37{ }^{\circ} \mathrm{C}$ in a humidified atmosphere with $5 \% \mathrm{CO}_{2}$ with medium changed every 3 days. Early-passage cells (6-8th passage) were used in the following experiments. Plumbagin (PLB; Sigma-Aldrich) was dissolved in dimethyl sulfoxide (DMSO; Sigma-Aldrich) and stocked at $100 \mathrm{mM}$, which was diluted to working concentrations with culture medium. ARPE-19 cells were cultured under two conditions: (1) with various concentration of plumbagin $(0,5,15$ or $25 \mu \mathrm{M})$ for $24 \mathrm{~h}$; or (2) with plumbagin at $15 \mu \mathrm{M}$ for 12,24 and $48 \mathrm{~h}$. The control cells received the vehicle $(0.05 \%$ DMSO) only.

\section{Microscopic studies}

ARPE-19 cells with PLB in various concentration were seeded in culture dishes and observed under an inverted microscope (Axiovert 200, Zeiss; Oberkochen, Germany). Then cells were fixed in $4 \%$ paraformaldehyde solution, then stained with $10 \mu \mathrm{g} / \mathrm{ml} \mathrm{4,6-diamidino-2-phenolindole}$ (DAPI; Sigma- Aldrich) to display the nuclei under a fluorescence microscope (BX53TR, Olympus; Japan).

\section{Cell viability and proliferation assay}

The 3-(4, 5 dimethyl-thiazol-2-yl)-2, 5-diphenyltetrazolium bromide (MTT) assay was performed to assess the effect of PLB on the viability of ARPE-19. Briefly, the ARPE cells were trypsinized, centrifuged, and seeded in 96-well (Thermo Fisher Scientific, Inc.) at a density of $8 \times 10^{3}$ cells/ well. After PLB treatment, cells in each well were incubated with $20 \mu \mathrm{L}$ of MTT $(5 \mathrm{mg} / \mathrm{mL})$ for a further $4 \mathrm{~h}$, then the crystals were dissolved with $150 \mu \mathrm{L}$ DMSO by shaking slowly for $10 \mathrm{~min}$. The absorbance was determined at the wavelengths of $540 \mathrm{~nm}$ using a fluorescence spectrophotometer (RF-6000, shimadzu; Japan).

\section{Assessment of cellular apoptosis}

The Annexin V-FITC/PI apoptosis detection kit (BD Biosciences Inc.; San Jose, CA, USA) were used to measure the number of apoptotic cells after ARPE cells were treated with PLB. Briefly, cells were trypsinized and collected at the indicated time points, then adjusted to concentration at $1 \times 10^{6} / \mathrm{ml}$, resuspended in $500 \mu \mathrm{l}$ buffer containing $5 \mu \mathrm{l}$ Annexin V-FITC, $5 \mu \mathrm{l}$ PI and incubated for $15 \mathrm{~min}$ in the dark at room temperature. The apoptotic cells were analyzed by FACSCalibur Flow Cytometer (Becton, Dickinson and Company; CA, USA) within $1 \mathrm{~h}$.

\section{Cell cycle distribution analysis}

After treatment as described previously, the cells were harvested and fixed with cold 70\% ethanol. Next, $100 \mu \mathrm{l}$ RNase A $(25 \mu \mathrm{g} / \mathrm{mL})$ and $400 \mu \mathrm{l}(50 \mu \mathrm{g} / \mathrm{mL})$ PI (DNA stainer; Sigma Aldrich; St. Louis, MO, USA) were added and incubated for $30 \mathrm{~min}$ in the dark room. At last, $1 \times$ $10^{4}$ cells of each sample were analyzed by a flow cytometer (Becton, Dickinson and Company; San Jose, CA, USA) at the wavelengths of $488 \mathrm{~nm}$.

\section{Western blot and ELISA}

The expression level of proliferative related proteins were assessed by Western blotting assays. The treated ARPE cells were lysed with RIPA buffer (Solario; Beijing, China) and protein contents were determined by Pierce ${ }^{\mathrm{TM}}$ bicinchoninic acid (BCA) protein assay kit (Thermo Fisher Scientific Inc; MA, USA). Each protein sample at $50 \mathrm{ng}$ and rainbow molecular weight markers (11$245 \mathrm{kDa}$, Solario, Beijing, China) were electrophoresed on $8 \%-10 \%$ sodium dodecyl sulfate polyacrylamide gel electrophoresis minigel (SDS-PAGE) after thermal denaturation at $95{ }^{\circ} \mathrm{C}$ for $5 \mathrm{~min}$. Proteins were electrotransferred onto polyvinylidene difluoride (PVDF) membranes (EMD Millipore; Billerica, MA, USA) at $100 \mathrm{~V}$ at $4{ }^{\circ} \mathrm{C}$ for $2 \mathrm{~h}$, then blocked with $5 \%$ non-fat milk. Subsequently, membranes were probed with indicated primary antibody against Bak (ab32371), Bax(ab32503), Bcl2(ab32124), Bcl-x(ab32370), p38 (phospho T180; ab178867), p-PI3K (phospho Y607; ab182651), $\beta$ Catenin(ab6302) and Notch1(ab83232) (Abcam; Cambridge,UK) at $4{ }^{\circ} \mathrm{C}$ overnight and then blotted with goat anti-rabbit horseradish peroxidase-conjugated secondary antibody (IgG; catalog no. 7074S; Cell Signaling Technology Inc.; MA, USA) for $1 \mathrm{~h}$ at room temperature according to the manufacturer's protocol. The protein bands were visualized using the Bio-Rad Chemi Doc ${ }^{\mathrm{TM}}$ XRS system (Bio-Rad Laboratories Inc.; CA, USA) and band density was measured using Image I image analytical software (National Institutes of Health,Bethesda, MD). The protein concentration was calculated based on the value of the internal control $\beta$-actin (ab32572) or glyceraldehyde-3-phosphate dehydrogenase (GAPDH; ab128915; Abcam; Cambridge, UK). Under the same cultured conditions, the level of Bax, Cytochrome C, Caspase- 3 and Caspase- 8 were determined by ELISA kits (Roche Biochemicals) following the manufacturer's instructions. 
RNA extraction and real-time PCR

ARPE-19 cells were cultured and treated as described previously. Afterwards, total RNA from $6 \times 10^{5}$ cells was extracted collected with Trizol reagent (Invitrogen; Carlsbad, USA) and quantified by spectrophotometry. Reverse transcription was then performed with RNA reverse transcription kit (TaKaRa; Japan). Afterwards, PCR was carried out with SYBR Green qRT-PCR kit (Thermo Fisher Scientific; MA, USA) according to the manufacturer's instructions for 40 cycles. Each cycle was composed of $30 \mathrm{~s}$ at $95^{\circ} \mathrm{C}$, $20 \mathrm{~s}$ at $55^{\circ} \mathrm{C}$ and $20 \mathrm{~s}$ at $72{ }^{\circ} \mathrm{C}$. The expression level of $\beta$ actin was set as control, whereas the mRNA expression level $\Delta \Delta \mathrm{Ct}=\mathrm{PLB}$ group [Ct (objective) $-\mathrm{Ct}(\beta$-actin)]-control group [Ct (objective)-Ct ( $\beta$-actin)].

\section{Statistical analysis}

The experiments were performed at least three times and data were expressed as mean \pm standard deviation (SD). SPSS version 22.0 (SPSS, Inc.; Chicago, USA) was used to perform statistical analyses. Differences between control and treated samples were evaluated by onewayanalysis of variance (ANOVA) followed by Tukey's multiple comparison procedure. And a Pearson test was performed for correlation. A value of $p<0.05$ was considered as statistically significant in each experiment.

\section{Results}

PLB inhibits the viability of ARPE cells

The effect of PLB on viability of ARPE cells was evaluated by MTT assay. In comparison to the control cells, the viability of cells exposed to PLB at 5, 15 or $25 \mu \mathrm{M}$ for $12 \mathrm{~h}$ were $95.17 \%, 79.18 \%$ and $66.53 \% ; 93.92 \%, 74.11 \%$ and $56.81 \%$ at $24 \mathrm{~h} ; 89.88 \%, 60.77 \%$ and $38.94 \%$ at $48 \mathrm{~h}$, respectively (Fig. 1a). The IC50 were 30.94, 26.67 and $20.43 \mu \mathrm{M}$ for ARPE cells after 12, 24 and 48 h' incubation with PLB, respectively.

In parallel, treated with various concentration of PLB after $24 \mathrm{~h}$, the ARPE cells appeared typical apoptosis morphological changes, such as cell shrinkage, lost normal spindle shape or broken under inverted optical microscope. The number of cells decreased with the increase of drug concentration. Furthermore, the nucleus pycnosis and cracking could be observed after DAPI staining, especially in cells with high concentration of PLB (Fig. 1b).

To sum up, these results proved that PLB had a potent anti-proliferative effect on ARPE cells.

\section{PLB induces apoptosis of ARPE cells}

The typical morphological changes occurred during the late apoptosis in ARPE cells have been demonstrated, so next we measured the effect of PLB on early apoptosis

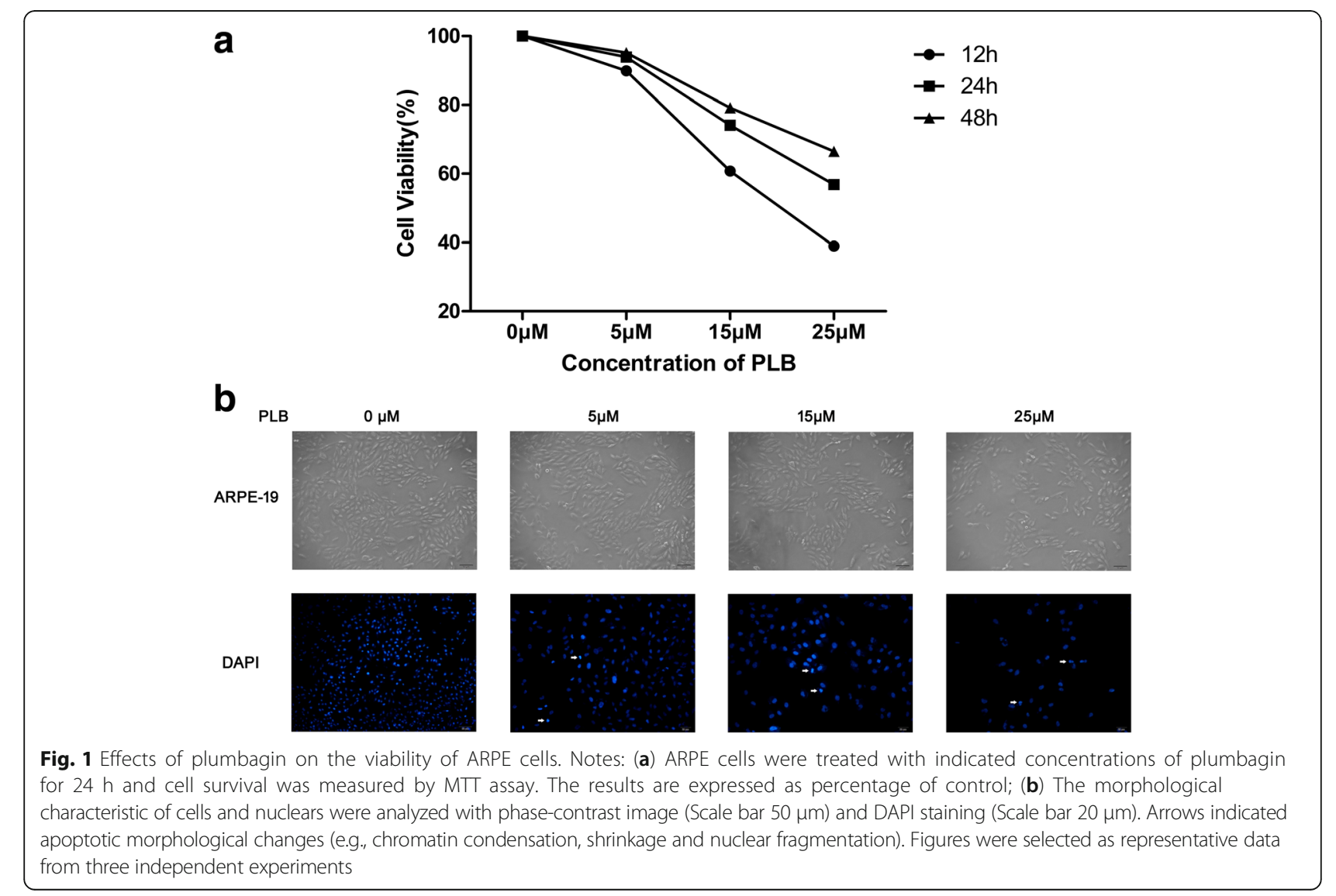


using Annexin V-FITC/PI staining analysis. After treated with PLB at 5,15 , and $25 \mu \mathrm{M}$ for $24 \mathrm{~h}$, the total percentage of apoptotic cells including early and late apoptosis stages were $(40.16 \pm 3.86) \%$, $(51.33 \pm 2.36) \%$ and $(75.43 \pm$ 1.85 \%, respectively. (Fig. 2a). Particularly, there was a remarkable rise in early, late or total apoptotic numbers when cells were incubated with $5 \mu \mathrm{M}$ PLB or more $(P<$ 0.001 ; Fig. $2 \mathrm{~b}$ ), and this progress was concentrationdependent (Pearson test; $P<0.001$ ). Furthermore, when ARPE cells were treated with $15 \mu \mathrm{M}$ PLB for 12,24 , and $48 \mathrm{~h}$ (Fig. 2c), the percentage of apoptotic cells was increased from $(0.57 \pm 0.40) \%$ at the basal line (time 0$)$ to $(55.30 \pm 6.37) \%, \quad(60.97 \pm 4.39) \% \quad$ and $\quad(75.13 \pm 1.72) \%$, time-dependently $(P<0.001$, Fig. $2 \mathrm{~d}$; Pearson test, $P=$ $0.001)$. These results indicated that PLB could induce apoptosis of ARPE cells prominently in a concentrationand time-dependent manner.

\section{PLB causes G2/M arrest in ARPE cells}

In order to further explore the anti-proliferative mechanism of PLB on ARPE cells, we examined the cell cycle distribution using flow cytometric analysis. Cell cycle distribution showed no significant change at $5 \mu \mathrm{M}$ for $24 \mathrm{~h}(P=0.850)$, whereas the percentage of $\mathrm{G} 2 / \mathrm{M}$ phase increased significantly in 15 and $25 \mu \mathrm{M}$ groups $(P=$ 0.038 and 0.000; Fig. 3a+b). Meanwhile, there was a 1.4-, 2.8-, and 4.9- fold increase in number of G2/M phase compared to the control group after cells were incubated with $15 \mu \mathrm{M}$ PLB for 12,24 , and $48 \mathrm{~h}$, respectively $(P=$
0.026,0.001,0.000; Fig. 3c+d). Furthermore, the results showed this progress was concentration-dependent (Pearson test; $P<0.001$ ) and time-dependent (Pearson test; $P=0.001$ ). However, PLB treatments did not significantly affect the G0/G1 and S phases at the same time.

\section{PLB modulates key apoptotic regulators in ARPE cells}

Since we have known the anti-proliferative effect of PLB on ARPE cells, we next assessed the expression of related proteins responsible for this phenomenon. Many factors are involved in drug-induced apoptosis, and the Bcl-2 family is a critical one. We examined the expression of pro-apoptotic proteins ( $\mathrm{Bax}, \mathrm{Bak}$ ) and anti-apoptotic proteins (Bcl-2, Bcl-xl) in ARPE cells by Western blot analysis (Fig. 4a). After treatment with 5, 15, and $25 \mu \mathrm{M}$ PLB for $24 \mathrm{~h}$, the level of Bax was increased by 1.7-, 2.1-, and 2.4-fold and the level of Bak was increased by 2.5-, 3.1-, and 4.6fold, compared to control cells, respectively (each $P<0.001$; Fig. $4 \mathrm{~b}$ ). In contrast, the level of $\mathrm{Bcl}-2$ was reduced by $74.8 \%, 49.9 \%$ and $13.6 \%$ respectively (each $P<0.001$; Fig. 4c) while the level of Bcl-xl was decreased by $80.9 \%, 67.8 \%$ and $57.8 \%$ compared to control cells $(P=0.001,0.000,0.000$; Fig. 4c). Furthermore, the differences between adjacent groups also have statistical significance $(P<0.05)$ and the changes was dependent on the concentration of PLB (Pearson test; $P<0.001)$.

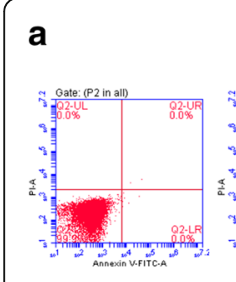

PLB ( $\mu \mathrm{M}) \quad 0$

C

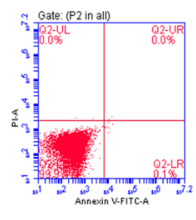

Time (hours) 0

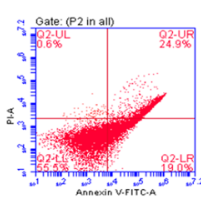

5

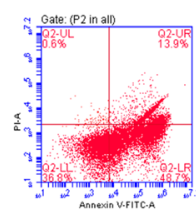

12

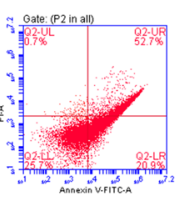

15

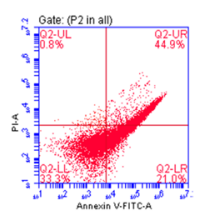

24

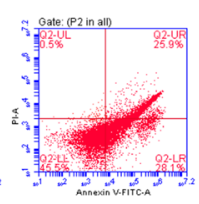

25

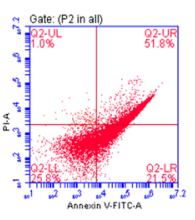

48
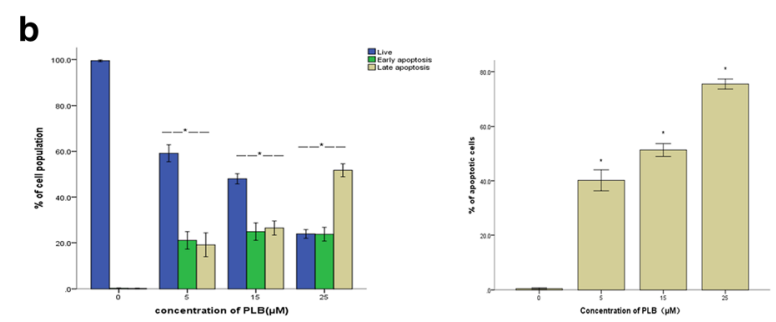

d

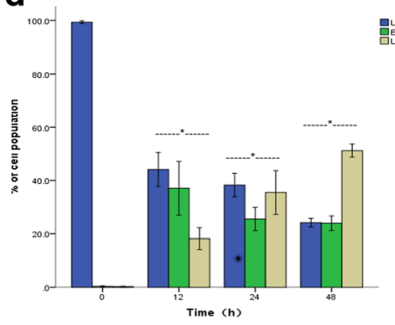

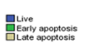

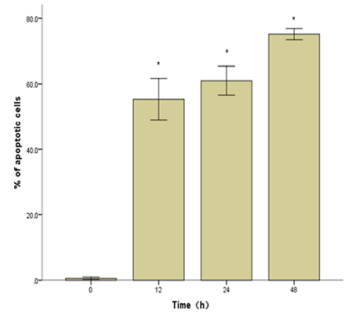

Fig. 2 Plumbagin enhanced apoptosis of ARPE cells. The apoptosis of cells was analyzed by Annexin V-FITC/PI assay. Data were represented the mean \pm SD of three individual experiments. ( ${ }^{*} P<0.05$ by one-way ANOVA.). Notes: (a) Flow cytometric plots show cells in the live, early apoptosis, and late apoptosis stages when the cells were treated with PLB at 0, 5, 15 and $25 \mu \mathrm{M}$ for 24 h; (b) Bar graphs show the percentage of specific cell populations (live, early apoptosis, or late apoptosis) and total apoptosis cell population when the cells were treated with PLB at 0, 5, 15, and $25 \mu \mathrm{M}$ for $24 \mathrm{~h}$; (c) Flow cytometric plots show cells in the live, early apoptosis, and late apoptosis stages when the cells were treated with $15 \mu \mathrm{M}$ PLB at 0, 12, 24,and 48 h; (d) Bar graphs show the percentage of specific cell populations (live, early apoptosis, or late apoptosis) and total apoptosis cell population when the cells were treated with $15 \mu \mathrm{M}$ PLB at $0,12,24$, and $48 \mathrm{~h}$ 

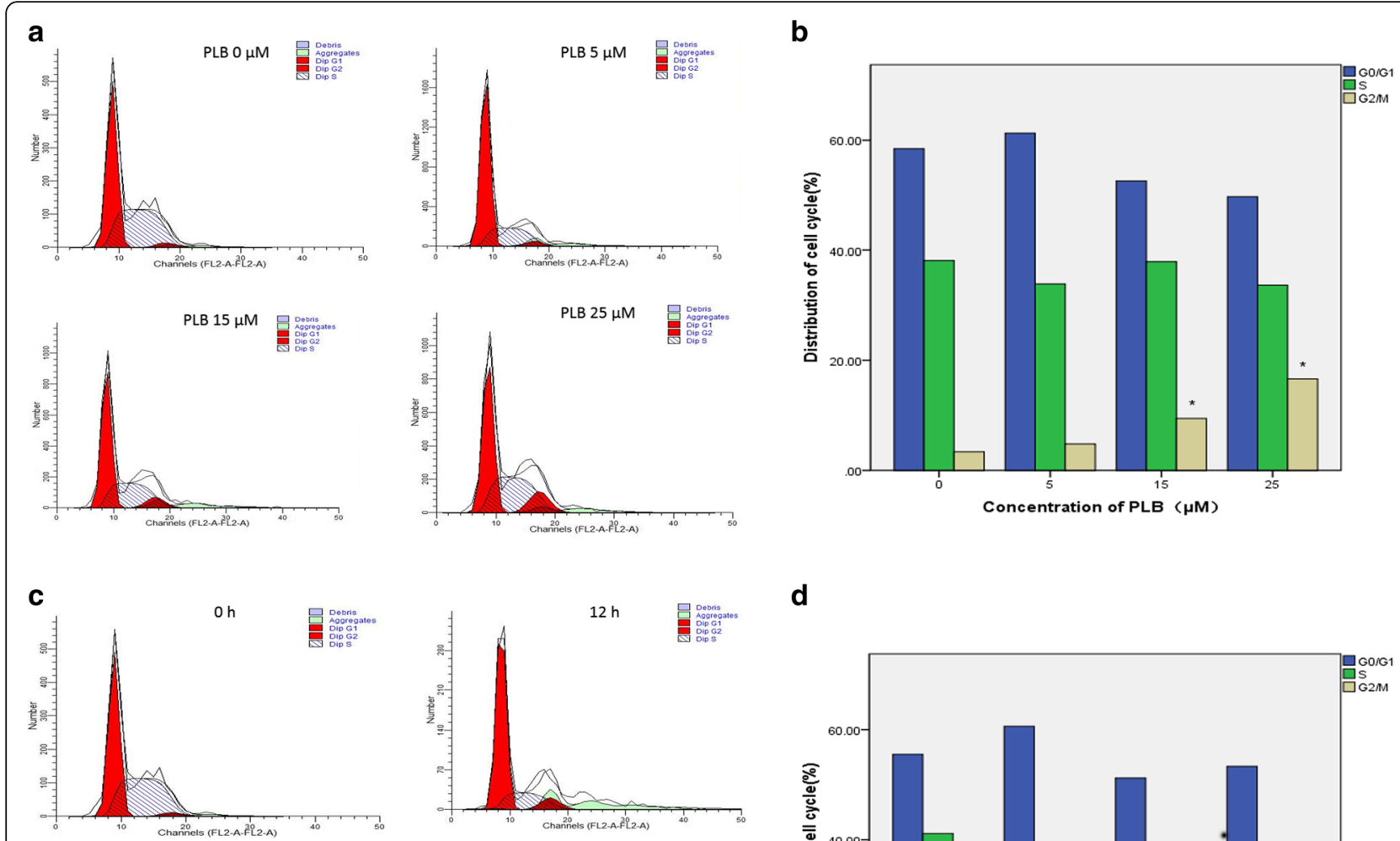

d
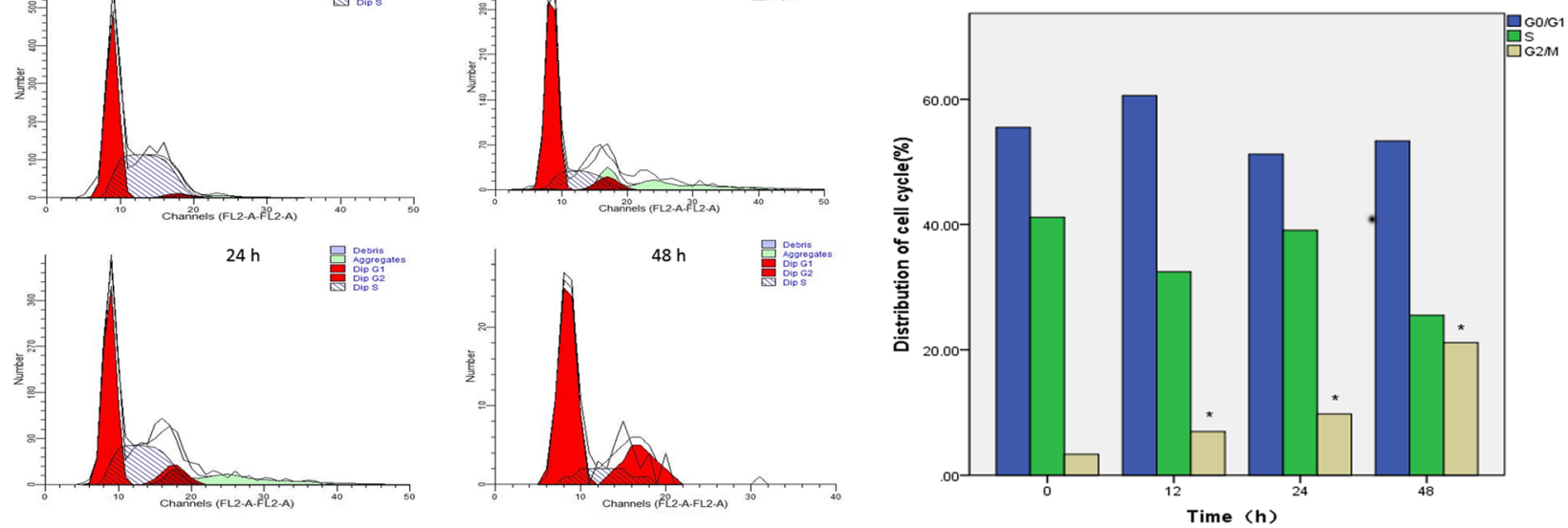

Fig. 3 Plumbagin induces G2/M in ARPE cells. The population of cells was analyzed by flow cytometry. Data represented the mean \pm SD of three individual experiments. ( $P<0.05$ by one-way ANOVA.). Notes: (a) Flow cytometric histograms show the cell cycle distribution when the cells were treated with PLB at $0,5,15$ and $25 \mu \mathrm{M}$ for $24 \mathrm{~h}$; (b) Bar graphs show the cell cycle distribution (G0/G1、S and G2/M phase) when the cells were treated with PLB at 0, 5, 15, and $25 \mu \mathrm{M}$ for $24 \mathrm{~h}$. c Flow cytometric histograms show the cell cycle distribution when the cells were treated with $15 \mu \mathrm{M}$ PLB at 0, 12, 24, and 48 h; (d) Bar graphs show the cell cycle distribution (G0/G1、S and G2/M phase) when the cells were treated with $15 \mu \mathrm{M} P L B$ at $0,12,24$, and $48 \mathrm{~h}$

The parallel exams showed that PLB regulates the expression of apoptotic proteins in a time-dependent manner as well (Pearson test; $P<0.001$ ). Briefly, the level of Bax was increased by 1.4-, 2. 1-and 2.7-fold, while Bak was increased by 2.1-, 3.1-, and 5.0-fold after incubation with $15 \mu \mathrm{M}$ PLB for 12, 24, and $48 \mathrm{~h}$ (each $P<0.001$; Fig. $4 \mathrm{~d}$ ). At the same time, the level of Bcl- 2 was reduced by $66.2 \%, 50.0 \%$ and $14.2 \%$ (each $P<0.001$; Fig. $4 \mathrm{e}$ ) and Bcl-xl was decreased by $77.3 \%, 70.5 \%$ and $57.6 \%$ compared to the control $(P=$ 0.026, 0.006, 0.001; Fig. 4e). The differences between adjacent groups had statistical significance except $\mathrm{Bcl}-\mathrm{xl}$ group $(P<0.05)$.

Moreover, the ELISA outcomes of Bax showed the same tendency as Western Blotting results, the downstream effect factors in endogenous apoptosis process such as Cytochrome $\mathrm{C}$ was increased by 1.49-, 1.66-, and 1.8-fold and Caspase-3 was increased by 1.96-, 2.34-, and 2.51-fold, compared to control cells respectively, after treatment with 5,15 , and $25 \mu \mathrm{M}$ PLB for $24 \mathrm{~h}$. While the level of Cytochrome $C$ was increased by 1.39-, 1. 76-and 1.90-fold, while Caspase- 3 was increased by 1.85-, 2.23-, and 2.40-fold after incubation with $15 \mu \mathrm{M}$ PLB for 12, 24, and $48 \mathrm{~h}$ (each $P<0.001$; Pearson test, $P$ $=0.001$ ). However, the content of exogenous apoptosis factor Caspase-8 did not show any significant differences. (Fig. 4f).

Taken together, these results demonstrated an upregulating role in the expression of pro-apoptotic proteins and a down-regulating role in the expression of anti-apoptotic proteins of PLB in ARPE cells. 

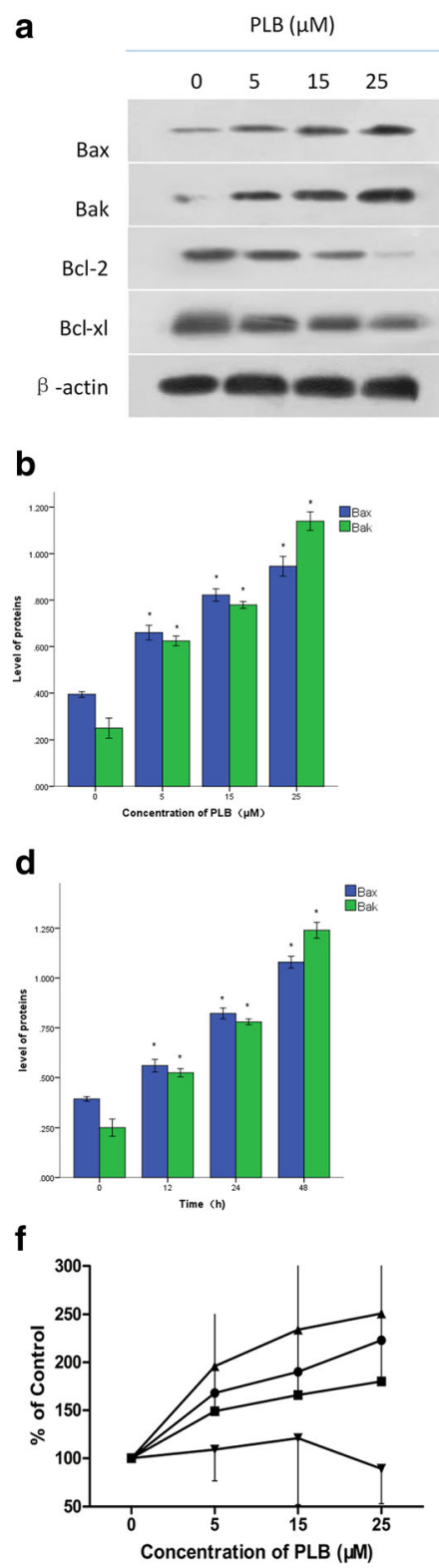

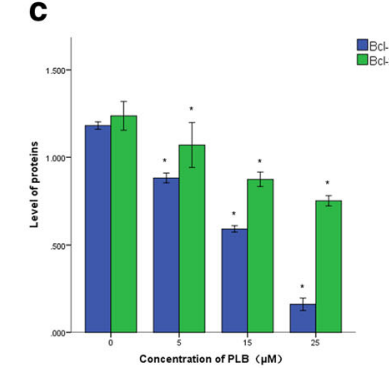

e
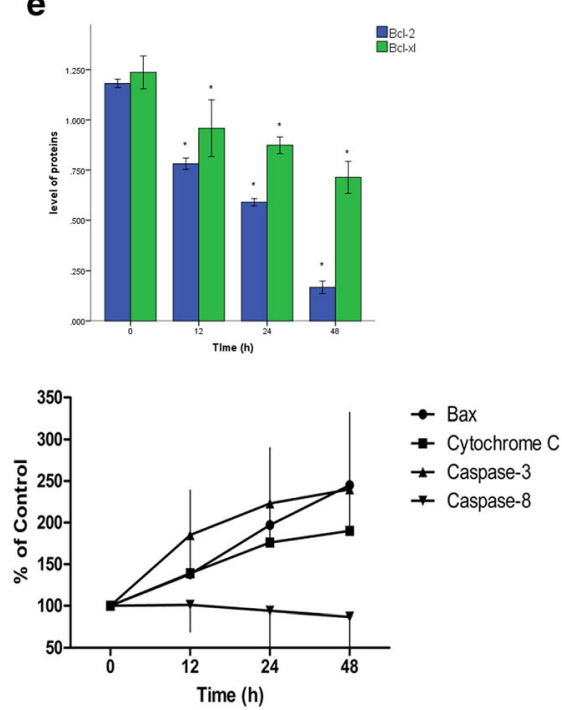

Fig. 4 Effect of plumbagin on the expression of apoptosis-related proteins in ARPE cells. (*:P<0.05 by one-way ANOVA, $n=3)$. Notes: (a) The expression levels of Bax, Bak, Bcl-2 and Bcl-xl determined by Western blotting assay when ARPE cells were treated with plumbagin at $0,5,15$ and $25 \mu \mathrm{M}$. $\beta$-actin was used as the internal control. b Bar graphs show the expression levels of Bax and Bak when ARPE cells were treated with plumbagin at 0,5,15 and $25 \mu \mathrm{M}$ for $24 \mathrm{~h}$. c Bar graphs show the expression levels of Bcl-2 and Bcl-xl when ARPE cells were treated with plumbagin at 0,5,15 and $25 \mu \mathrm{M}$ for $24 \mathrm{~h}$. d Bar graphs show the expression levels of Bax and Bak when ARPE cells were treated with plumbagin at $15 \mu \mathrm{M}$ for $0,12,24$ and $48 \mathrm{~h}$. e Bar graphs show the expression levels of $\mathrm{BCl}-2$ and $\mathrm{BCl}-\mathrm{xl}$ when $\mathrm{ARPE}$ cells were treated with plumbagin at $15 \mu \mathrm{M}$ for $0,12,24$ and $48 \mathrm{~h}$. $\mathbf{f}$ The expression levels of Bax, Cytochrome C, Caspase-3 and Caspase-8 determined by ELISA when ARPE cells were treated with plumbagin at 0,5,15 and $25 \mu \mathrm{M}$ for $48 \mathrm{~h}$

\section{PLB suppresses P38MARK and PI3K axis in ARPE cells} Upon the observation that PLB can inhibit the proliferation and induce cell apoptosis in ARPE cells, next step we tried to explore the underlying mechanisms. It is well known that p38 MAPK, PI3K-AKT-mTOR, Wnt/ $\beta$-catenin and Notch signaling pathways play an important role in cell proliferation and work actively during the formation and development of PVR. First, we examined the mRNA relative expression of symbolic tic parts of these signaling pathways: p38 MARK, PI3K, $\beta$-catenin and Notch-1 using Real-time Quantitative PCR Detecting System. The results showed PLB prominently inhibited the expression of p38 MARK and PI3K mRNA a concentration-dependently (Pearson test; $P=0.001$, 
0.000 , respectively). The production of p38 MARK was decreased by $12.0 \%, 21.0 \%$, and $26.7 \%$ when the cells were incubated with 5,15 and $25 \mu \mathrm{M}$ PLB, respectively $(P=0.232,0.026,0.007$; Fig. 5a). Similarly, the PI3K level was decreased by $15.7 \%, 35.4 \%$, and $41.0 \%$ in comparison to the control group, respectively $(P=0.083,0.001,0.000$; Fig. 5a). However, the expression of $\beta$-catenin and Notch-1 had no significant change (Fig. 5a). Furthermore, when ARPE cells were treated with $15 \mu \mathrm{M}$ PLB for 12,24 , and $48 \mathrm{~h}$, there was a $27.7 \%, 26.4 \%$, and $32.7 \%$ reduction in p38 MARK mRNA $(P=0.006,0.008,0.002)$ while $25.7 \%$, $39.0 \%$, and $43.0 \%$ decrease in PI3K mRNA $(P=0.032$, 0.003, 0.002; Fig. 5b). In addition, these PLB-induced down-regulation of both pathways were in a timedependent manner (Pearson test; $P=0.008,0.002$, respectively). In a word, the above-mentioned results indicated that PLB could affect p38 MARK and PI3K signaling but do not affect $\beta$-catenin or Notch signaling pathways in ARPE cells.

We also observed the relevant proteins as symbolic downstream effector of the signaling pathways using Western blotting, to examine whether PLB had the same effect on direct factors of cell proliferation (Fig. 5c). After incubation with PLB at series of concentration, the content of p-p38MARK was significantly decreased from 1.06 at base level to $0.91,0.62$ and 0.56 dose-dependently $(P=0.045,0.000,0.000$; Pearson test, $P<0.001)$. Further, the production of p-PI3K was notably descended from 1.74 at the basal level to $1.53,1.41$, and 1.21 dose-dependently ( $P$
$=0.010,0.000,0.000$; Pearson test, $P<0.001)$. Nevertheless, there was a slight decrease in $\beta$-catenin content, but only the reduction at the highest concentration $(25 \mu \mathrm{M})$ had a statistical significance $(P=0.498,0.125,0.000)$. The expression changes of Notch-1 had no statistically significantly differences, neither $(P=0.825,0.795,0.125$; Fig. $5 d)$. In parallel exams, when ARPE cells were exposed to $15 \mu \mathrm{M}$ PLB for 12,24 , and $48 \mathrm{~h}$, there was a $21.8 \%, 45.1 \%$, and $46.8 \%$ reduction in the content of p-P38 MARK $(P=0.009,0.000$, $0.000) ; 9.6 \%, 19.8 \%$, and $23.2 \%$ decrease in p-PI3K $(P=$ $0.027,0.000,0.000) ; 2.8 \%, 30.2 \%$, and $39.6 \%$ decline in $\beta$ catenin $(P=0.944,0.002,0.000) ; 7.5 \%, 20.5 \%$, and $22.6 \%$ drop in Notch-1 $(P=0.346,0.005,0.003$; Fig. $5 e)$, respectively. Only the levels of p-p38MARK and p-PI3K proteins had statistical significant differences at each time point, and attenuated in a time-dependent manner (Pearson test; $P<0.001)$.

In conclusion, PLB has a potent anti-proliferative effect on ARPE cells by inhibiting p38 MAPK and PI3K/ Akt/mTOR signaling pathways, not directly blockage of Wnt/ $\beta$-catenin and Notch signaling pathways.

\section{Discussion}

Proliferative vitreoretinopathy (PVR) remains an enormous challenge for vitreoretinal doctors. Recent efforts have been directed toward the biochemical inhibition of cellular proliferation and membrane formation [10]. Analyses of epiretinal membranes from patients, as well as animal models of experimental PVR, have regarded RPE cells as the key factor in triggering PVR development.

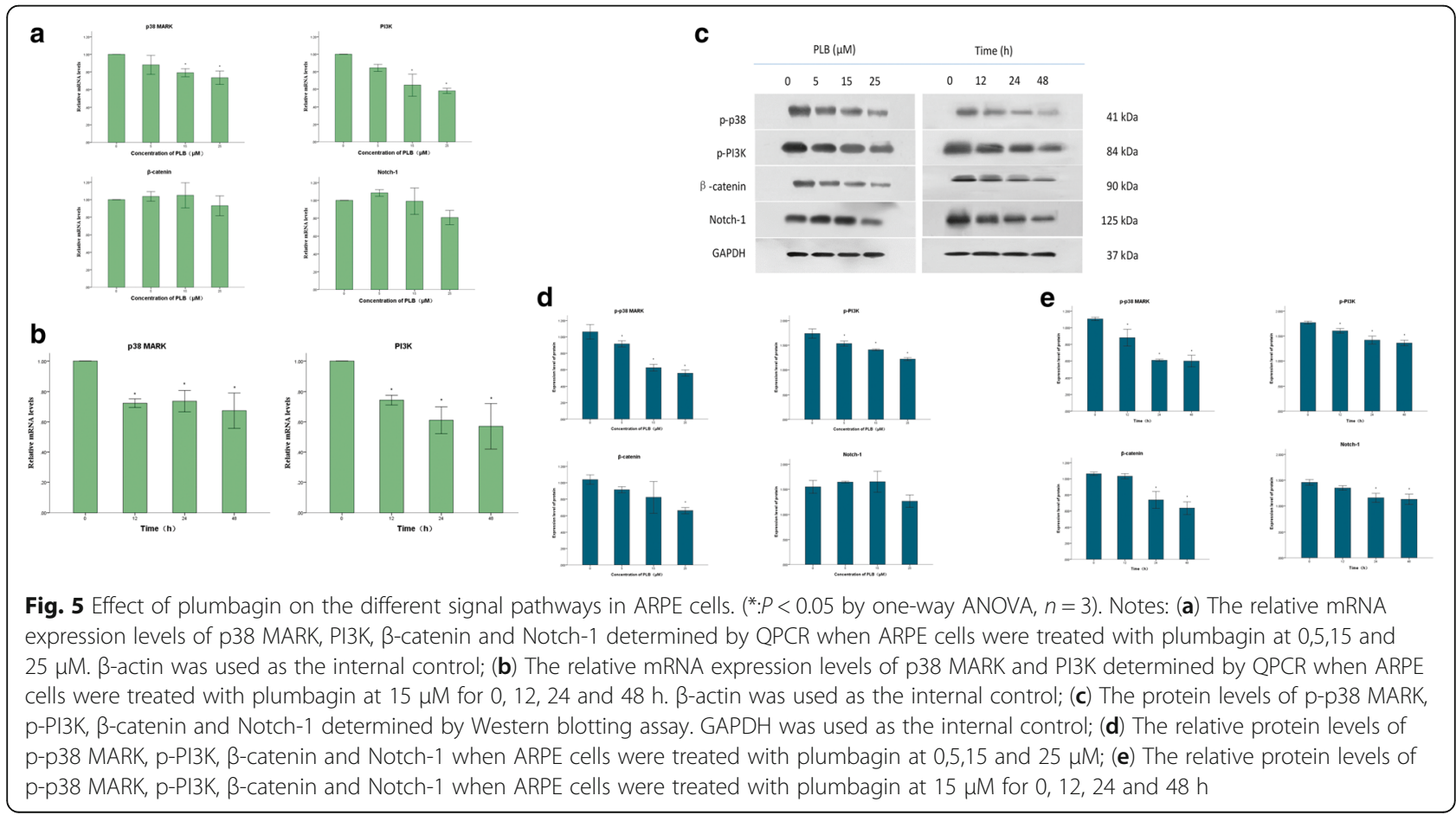


Therefore, we choose them as investigated subjects to predict the effects of biochemical drugs on PVR. ARPE-19 is a human RPE cell line which has similar characters of the RPE cells in vivo and is widely used as an in vitro model for investigation [11, 12]. Hence, ARPE-19 cells were used in our present study to find out the efficacy of plumbagin on RPE cells and PVR.

PLB, a natural compound, has shown potent antiproliferative effects by regulating various signaling pathways related to cell cycle and apoptosis [3, 6-8, 13-17]. However, whether PLB plays a similar role in RPE cells is unknown as yet. In present study, we demonstrated that PLB promoted cell cycle arrest and apoptosis through PI3K/Akt/mTOR- and p38 MAPK-mediated pathways in ARPE-19 cells, which may benefit the prophylaxis of PVR.

Cell cycle is an important part of cell proliferation including a long growth phase (G1), a DNA replicating phase (S), a short growth phase (G2), and cell division (mitosis, M), and any abnormality in cell cycle may cause apoptosis [18]. We assess the influence of PLB on cell cycle distribution of ARPE-19. Our results from flow cytometry indicate that PLB causes cell cycle arrest at G2/M phase concentration- and time-dependently, consequently prevents cell proliferation and induce cell apoptosis [19].

Apoptosis is a precisely programmed procedure of cell death in order to maintain cellular homeostasis [20]. However, RPE cells in PVR proliferate in an uncontrolled manner and are resistant to apoptosis. We observed that PLB had the capacity to sensitize ARPE cells toward apoptosis. Moreover, the higher of the concentration, the longer of drug duration, there were more numbers of apoptotic cells from early stage to late stage. Treated with $25 \mu \mathrm{M}$ PLB for $24 \mathrm{~h}$ or with $15 \mu \mathrm{M}$ PLB for $48 \mathrm{~h}$, percentage of apoptotic cells were both over $75 \%$. Herein, PLB showed a remarkable ability to promote apoptosis. These results are consistent with previously published reports suggesting the apoptosis inducing potential of PLB in various cell lines [7, 13, 17].

At a molecular level, the Bcl-2 family proteins regulate the intrinsic apoptosis by changing the permeability of mitochondrial membrane [21]. The proapoptotic members Bax and Bak release apoptogenic molecules (such as cyt $\mathrm{C}$ ), leading to caspase activation, while the anti-apoptotic members, such as Bcl-2 and Bcl$x L$, restrain Bax and Bak [22]. In our experiment, PLB possesses an up-regulating ability in the expression of proapoptotic proteins and a down-regulating role in the expression of anti-apoptotic proteins of PLB in ARPE cells. The downstream effectors such as Cytochrome $C$ and Caspase- 3 changed accordingly. In fact, plenty of previous studies have demonstrated the similar effect of PLB on other cancer cell lines $[7,23]$. Thus, it could be inferred that the modulation effect of PLB on Bcl-2 family proteins plays an important role in promoting apoptosis in ARPE cells.

At a gene signal level, PVR is a complex process involving intricate interplay between multiple signaling pathways, such as p38 MAPK, PI3K-AKT-mTOR, Wnt/ $\beta$-catenin and Notch. In the present study, we have explored that plumbagin suppressed the expression of p38 MAPK and PI3K, which may be the key contributors to ARPE apoptosis.

Mitogen-activated protein kinases (MAPKs) play a momentous role in controlling cell proliferation as signal transducing enzymes, while p38 MARK is one of the key parts [24]. Yamaguchi, K. et al. [25] has reported it functioned in rat cultured RPE cells and its inhibitor could arrest cell cycle progression. In our study, PLB doseand time-dependently inhibited the expression of p38 MARK mRNA and protein, then reduced the proliferation of ARPE cells. Thus, the restraint of p38 MARK signaling pathway may partly contribute to the affect of PLB in ARPE cells.

In our study, we also observed that PLB predominantly inhibit PI3K-AKT-mTOR axis in the same manner. The $\mathrm{PI} 3 \mathrm{~K} / \mathrm{Akt} / \mathrm{mTOR}$ signaling is an important pathway related to cell survival. Normally, PI3K activates serine/ threonine kinase Akt, then trigger serine/threonine kinase mTOR, at last inhibit cell death and promote cell survival [26]. It has been stated that thrombin promotes RPE cell proliferation through this PI3K/Akt/mTOR pathway [27]. Also, Liegl R. et al. [28] reported inhibition of mTOR pathway with temsirolimus could consistently suppress proliferation and migration of RPE. Our results indicated that PLB decreased PI3K expression on RNA and protein levels significantly. We therefore consider that PLB act as an inhibitor of PI3K/Akt/mTOR signaling pathway as well in ARPE cells. What's more, AKT is also a G2-M initiator, which may explain the G2/M arrest of ARPE cells exposed to PLB. Till now, several investigators have revealed that PLB exhibited its apoptosis-inducing effect by inhibition of PI3K/Akt/ mTOR way in other cell lines $[3,9,29]$, which are consistent with our consequence.

In fact, there are several other signaling pathways in the proliferation of RPE cells, such as Wnt/ $\beta$-catenin, Notch, Rho-ROCK and so on. Recent studies suggest suppressing the Wnt/beta-catenin signaling pathway may inhibit the propagation of RPE cells [30, 31]. Liu W. et al. [32] also reported the blockage of Notch signaling inhibited the proliferation of RPE cells. On the other hand, previous studies have revealed that PLB was able to restrain Wnt/ $\beta$-catenin and Notch signaling pathways. Nevertheless, in our study, PLB has not exhibited an obvious blockage on both signaling pathways in ARPE cells. The numerical fluctuations may be due to the cell 
number changes, or because of crosstalk and interaction between different signal networks, which need more complicated study to explore.

\section{Conclusions}

This study shows that plumbagin (1) induces apoptosis in ARPE cells in vitro; (2) the apoptosis may be associated with G2/M cell cycle arrest; (3) plumbagin inhibits cell proliferation by increasing pro-apoptotic proteins and decreasing anti-apoptotic proteins; (4) plumbagin induces ARPE cell death by inhibition of the p38 MARK and PI3K/AKT/mTOR pathways. These data provide primary evidence for the usage of PLB in PVR. Further in vivo studies are needed to ascertain the chemotherapy effects of PLB and more detailed mechanism should be elucidated in the future.

\footnotetext{
Abbreviations

DAPI: 4, 6-diamidino-2-phenolindole; DMSO: Dimethyl sulfoxide; GAPDH: Glyceraldehyde-3-phosphate dehydrogenase; MAPKs: Mitogenactivated protein kinases; MTT: 3-(4, 5 dimethyl-thiazol-2-yl)-2, 5diphenyltetrazolium bromide; PLB: Plumbagin; PVDF: Polyvinylidene difluoride; PVR: Proliferative vitreoretinopathy; RPE: Retinal pigment epithelial; SDS-PAGE: Sodium dodecyl sulfate polyacrylamide gel electrophoresis minigel
}

\section{Acknowledgments}

Not applicable.

\section{Funding}

No funding was obtained for this study.

\section{Availability of data and materials}

The datasets used and analysed during the current study are available from the corresponding author on reasonable request.

\section{Authors' contributions}

HC contributions to design of the study, acquisition of data, analysis and interpretation of data, and drafting the article. HW contributions to assist the exam and acquisition of data. JA and QS participated in the designment of the study and modify the discussion. JM contributions to conception and design, resolution of major issues and modification of the manuscript. All authors read and approved the final manuscript.

\section{Authors' information}

Prof. JM is the deputy director of Ophthalmology Department of Second Hospital of Hebei Medical University, also a well known specialist majoring vitreoretinopathy in China. JA and QS are the experts of vitreoretinopathy who majors in therapy in PVR. HW and HC are fellows in this department. All members of this group have experience in experimental studies.

\section{Ethics approval and consent to participate}

Not applicable.

\section{Consent for publication}

Not applicable.

\section{Competing interests}

The authors declare that they have no competing interests. All authors have agreed to authorship and order of authorship for this manuscript and that all authors have the appropriate permissions and rights to the reported data.

\section{Publisher's Note}

Springer Nature remains neutral with regard to jurisdictional claims in published maps and institutional affiliations.

\section{Author details}

'Department of Ophthalmology, Second Hospital of Hebei Medical University, No. 215 Peace West Road, Qiaoxi District, Shijiazhuang, Hebei 050000, China. ${ }^{2}$ Department of Ophthalmology, Cangzhou Central Hospital, No. 16 Xinhua West Road, Cangzhou, Hebei 061000, China.

Received: 19 June 2017 Accepted: 2 March 2018

Published online: 13 March 2018

\section{References}

1. Asaria RH, Charteris DG. Proliferative vitreoretinopathy: developments in pathogenesis and treatment. Compr Ophthalmol Updat. 2006;7(4):179-85.

2. Khan MA, Brady CJ, Kaiser RS. Clinical management of proliferative vitreoretinopathy: an update. Retina. 2015;35(2):165-75.

3. Pan ST, Qin Y, Zhou ZW, He ZX, Zhang X, Yang T, Yang YX, Wang D, Qiu JX, Zhou SF. Plumbagin induces G2/M arrest, apoptosis, and autophagy via p38 MAPK- and PI3K/Akt/mTOR-mediated pathways in human tongue squamous cell carcinoma cells. Drug Des Devel Ther. 2015;9:1601-26.

4. Pastor JC, Rojas J, Pastor-Idoate S, Di Lauro S, Gonzalez-Buendia L, Delgado-Tirado S. Proliferative vitreoretinopathy: a new concept of disease pathogenesis and practical consequences. Prog Retin Eye Res. 2016:51:125-55.

5. Padhye S, Dandawate P, Yusufi M, Ahmad A, Sarkar FH. Perspectives on medicinal properties of plumbagin and its analogs. Med Res Rev. 2012;32(6): $1131-58$.

6. Yang SJ, Chang SC, Wen HC, Chen CY, Liao JF, Chang CH. Plumbagin activates ERK1/2 and Akt via superoxide, Src and PI3-kinase in 3T3-L1 cells. Eur J Pharmacol. 2010;638(1-3):21-8.

7. Tian L, Yin D, Ren Y, Gong C, Chen A, Guo FJ. Plumbagin induces apoptosis via the p53 pathway and generation of reactive oxygen species in human osteosarcoma cells. Mol Med Rep. 2012;5(1):126-32.

8. Wang CC, Chiang YM, Sung SC, Hsu YL, Chang JK, Kuo PL. Plumbagin induces cell cycle arrest and apoptosis through reactive oxygen species/CJun N-terminal kinase pathways in human melanoma A375.S2 cells. Cancer Lett. 2008;259(1):82-98.

9. Kuo PL, Hsu YL, Cho CY. Plumbagin induces G2-M arrest and autophagy by inhibiting the AKT/mammalian target of rapamycin pathway in breast cancer cells. Mol Cancer Ther. 2006;5(12):3209-21.

10. Kwon OW, Song JH, Roh Ml. Retinal detachment and proliferative vitreoretinopathy. Dev Ophthalmol. 2016;55:154-62.

11. Dunn KC, Aotaki-Keen AE, Putkey FR, Hjelmeland LM. ARPE-19, a human retinal pigment epithelial cell line with differentiated properties. Exp Eye Res. 1996;62(2):155-69.

12. Giddabasappa A, Bauler MN, Barrett CM, Coss CC, Wu Z, Miller DD, Dalton JT, Eswaraka JR. GTx-822, an ER\{beta\}-selective agonist, protects retinal pigment epithelium (ARPE-19) from oxidative stress by activating MAPK and PI3-K pathways. Invest Ophthalmol Vis Sci. 2010;51(11):5934-42.

13. Xue Y, Meng X, Ma L, Yuan Z. Plumbagin exhibits an anti-proliferative effect in human osteosarcoma cells by downregulating FHL2 and interfering with Wnt/B-catenin signalling. Oncology letters.2016;12(2):1095-100.

14. Niu M, Cai W, Liu H, Chong Y, Hu W, Gao S, Shi Q, Zhou X, Liu X, Yu R. Plumbagin inhibits growth of gliomas in vivo via suppression of FOXM1 expression. J Pharmacol Sci. 2015;128(3):131-6.

15. Shieh JM, Chiang TA, Chang WT, Chao CH, Lee YC, Huang GY, Shih YX, Shih YW. Plumbagin inhibits TPA-induced MMP-2 and u-PA expressions by reducing binding activities of NF-kappaB and AP-1 via ERK signaling pathway in A549 human lung cancer cells. Mol Cell Biochem. 2010; 335(1-2):181-93.

16. Courboulin A, Barrier M, Perreault T, Bonnet P, Tremblay VL, Paulin R, Tremblay Ė, Lambert C, Jacob MH, Bonnet SN, et al. Plumbagin reverses proliferation and resistance to apoptosis in experimental PAH. Eur Respir J. 2012;40(3):618-29

17. Hafeez BB, Jamal MS, Fischer JW, Mustafa A, Verma AK. Plumbagin, a plant derived natural agent inhibits the growth of pancreatic cancer cells in in vitro and in vivo via targeting EGFR, Stat3 and NF-KB signaling pathways. Int J Cancer. 2012;131(9):2175-86.

18. Williams GH, Stoeber K. The cell cycle and cancer. J Pathol. 2012;226(2):352-64.

19. Scatena R. Mitochondria and cancer: a growing role in apoptosis, cancer cell metabolism and dedifferentiation. Adv Exp Med Biol. 2012;942:287-308.

20. Alenzi FQ, Salem ML, Alyagoub FS, Alanazi FG, Alanazi WG, Alanazi MG, Alanazi AG, Alanazi MG, Al-Shehri H, Abuderman AA, et al. Apoptotic 
proteins and cancer: many faces. J Ayub Med Coll Abbottabad. 2012; 24(1):111-5.

21. Antico Arciuch VG, Elguero ME, Poderoso JJ, Carreras MC. Mitochondrial regulation of cell cycle and proliferation. Antioxid Redox Sign. 2012;16(10): 1150-80.

22. Zhou F, Yang Y, Xing D. BCl-2 and BCl-xL play important roles in the crosstalk between autophagy and apoptosis. FEBS J. 2011;278(3):403-13.

23. Kawiak A, Zawacka-Pankau J, Lojkowska E. Plumbagin induces apoptosis in Her2-overexpressing breast cancer cells through the mitochondrialmediated pathway. J Nat Prod. 2012;75(4):747-51.

24. Sui X, Kong N, Ye L, Han W, Zhou J, Zhang Q, He C, Pan H. p38 and JNK MAPK pathways control the balance of apoptosis and autophagy in response to chemotherapeutic agents. Cancer Lett. 2014;344(2):174-9.

25. Yamaguchi K, Tomita H, Sugano E, Nakazawa T, Tamai M. Mitogen-activated protein kinase inhibitor, PD98059, inhibits rat retinal pigment epithelial cell replication by cell cycle arrest. Jpn J Ophthalmol. 2002;46(6):634-9.

26. Hennessy BT, Smith DL, Ram PT, Lu Y, Mills GB. Exploiting the PI3K/AKT pathway for cancer drug discovery. Nat Rev Drug Discov. 2005;4(12):988-1004.

27. Parrales A, Lopez E, Lee-Rivera I, Lopez-Colome AM. ERK1/2-dependent activation of $\mathrm{mTOR} / \mathrm{mTORC} 1 / \mathrm{p} 70 \mathrm{~S} 6 \mathrm{~K}$ regulates thrombin-induced RPE cell proliferation. Cell Signal. 2013;25(4):829-38.

28. Liegl R, Koenig S, Siedlecki J, Haritoglou C, Kampik A, Kernt M. Temsirolimus inhibits proliferation and migration in retinal pigment epithelial and endothelial cells via mTOR inhibition and decreases VEGF and PDGF expression. PLoS One. 2014;9(2):e88203.

29. Wang F, Wang Q, Zhou ZW, Yu SN, Pan ST, He ZX, Zhang X, Wang D, Yang $Y X$, Yang $T$, et al. Plumbagin induces cell cycle arrest and autophagy and suppresses epithelial to mesenchymal transition involving PI3K/Akt/mTORmediated pathway in human pancreatic cancer cells. Drug Des Devel Ther 2015:9:537-60.

30. Zhou J, Jiang J, Wang S, Xia X. DKK1 inhibits proliferation and migration in human retinal pigment epithelial cells via the Wnt/beta-catenin signaling pathway. EXP THER MED. 2016;12(2):859-63.

31. Umazume K, Tsukahara R, Liu L, Fernandez De Castro JP, McDonald K, Kaplan HJ, Tamiya S. Role of retinal pigment epithelial cell $\beta$-catenin signaling in experimental proliferative vitreoretinopathy. Am J Pathol. 2014; 184(5):1419-28.

32. Liu W, Jin G, Long C, Zhou X, Tang Y, Huang S, Kuang X, Wu L, Zhang Q, Shen $\mathrm{H}$. Blockage of notch signaling inhibits the migration and proliferation of retinal pigment epithelial cells. ScientificWorldJournal. 2013;2013:178708.

\section{Submit your next manuscript to BioMed Central and we will help you at every step:}

- We accept pre-submission inquiries

- Our selector tool helps you to find the most relevant journal

- We provide round the clock customer support

- Convenient online submission

- Thorough peer review

- Inclusion in PubMed and all major indexing services

- Maximum visibility for your research

Submit your manuscript at www.biomedcentral.com/submit

) Biomed Central 